\title{
The Association of the Original OSHA Chemical Hazard Communication Standard with Reductions in Acute Work Injuries/IIInesses in Private Industry and the Industrial Releases of Chemical Carcinogens
}

\begin{abstract}
Arthur Oleinick, MD, JD, MPH*
Background OSHA predicted the original chemical Hazard Communication Standard (HCS) would cumulatively reduce the lost workday acute injury/illness rate for exposure events by $20 \%$ over 20 years and reduce exposure to chemical carcinogens.

Methods JoinPoint trend software identified changes in the rate of change of BLS rates for days away from work for acute injuries/illnesses during 1992-2009 for manufacturing and nonmanufacturing industries for both chemical, noxious or allergenic injury exposure events and All other exposure events. The annual percent change in the rates was used to adjust observed numbers of cases to estimate their association with the standard. A casecontrol study of EPA's Toxic Release Inventory 1988-2009 data compared carcinogen and non-carcinogens' releases.

Results The study estimates that the HCS was associated with a reduction in the number of acute injuries/illnesses due to chemical injury exposure events over the background rate in the range 107,569-459,395 (Hudson method/modified BIC model) depending on whether the HCS is treated as a marginal or sole factor in the decrease. Carcinogen releases have declined at a substantially faster rate than control non-carcinogens.

Discussion The previous HCS standard was associated with significant reductions in chemical event acute injuries/illnesses and chemical carcinogen exposures. Am. J. Ind. Med. 57:138-152, 2014. (c) 2013 Wiley Periodicals, Inc.
\end{abstract}

KEY WORDS: JoinPoint regression; OSHA standards; chemical hazards; chemical releases; epidemiology

Department of Environmental Health Sciences, School of Public Health, University of Michigan, Ann Arbor, Michigan

Disclosure Statement: The authors report no conflicts of interests.

${ }^{1}$ Associate Professor of Public Health Law Emeritus.

Abbreviations: AAPC, average annual percent change; APC, annual percent change; BIC, Bayesian information criterion; CNA, chemical, noxious, allergenic; DAFW, days away from work; FTE, full time equivalent; HCS, hazard communication standard; IARC, International Agency for Research on Cancer; ICD, InternationalClassification of Diseases; MSDS, material safety data sheet; NAICS, North American industry classification system;
NTP, national toxicology program;ODI,OSHAdatainitiative;OIICM,occupationalinjuryand illness classification manual; PEL, permissible exposure limit; SIC, standard industrial classification; TRI, toxic release inventory.

*Correspondence to: Arthur Oleinick, MD, JD, MPH, 2016 Vinewood Blvd, Ann Arbor, MI 48104.

E-mail:aoleinic@umich.edu

Accepted 23 September 2013

D0I10.1002/ajim.22269. Published online16 November 2013 in Wiley Online Library (wileyonlinelibrary.com). 


\section{INTRODUCTION}

The American worker needs a strong and effective chemical hazard communication standard (HCS) because of OSHA's stunning inability to carry out its statutory mandate to issue standards to control exposure to specific "toxic materials" [Code, 2011a]. The numbers stand in mute testimony to this need: more than 84,000 individual chemical substances listed on the Toxic Substances Control Act Inventory since 1978 indicating they are, or were, for sale in the United States [EPA, 2008, 2013a]; more than 130,000 substances with unique Chemical Abstract identifiers with at least one toxicity/hazard report on the National Institute of Occupational Safety and Health's Registry of Toxic Effects of Chemical Substances [NIOSH, 2011; CCOSH, 2013]; and an estimated 880,000 chemical or chemical mixture products requiring warnings on the label and/or the material safety data sheet (MSDS) under the previous version of the HCS [PPE, 2009].

In contrast, OSHA has issued 31 substance-specific standards involving 42 specific chemicals [CFR, 2012a] under its standard notice-and-comment procedures [Code, 2011a,b] since 1971, less than one a year. Hazard information for some 170 chemicals (some overlap) is required as part of OSHA's hazardous process standard [CFR, 2012b]. OSHA also issued permissible exposure limit standards (PEL) for some 400 hazardous chemicals alone or in mixtures [CFR, 2012c] by the time a special statutory provision that authorized adoption of such industry consensus standards expired in 1972 [Code, 2011c] and has been stymied since in its effort to update them [AFL-CIO, 1992]. The agency's failure to try again is puzzling because the Court upheld OSHA's authority to issue generic standards to update PELs. The current PELs involved thus represent 40-year-old science. The discrepancy between the numbers in this and the previous paragraph establish that the individual worker is dependent on the chemical HCS [CFR, 2012d] for warning information that she/he can use to assure needed protection or to request substitution of a less toxic material.

By a strong standard the author means a standard that requires communication of chemical hazard(s) as soon as there is credible data establishing the hazard that a reasonable worker would find useful in deciding on whether or not to request protection or use of a less hazardous compound. Such a standard should also provide a "bright line" criterion for when to communicate the hazard so that there is minimum variability in the decision of those who must identify the hazard.

As to effectiveness, the Supreme Court's seminal decision involving an early benzene exposure standard [Ind. Union, 1980a] interpreted OSHA's standard-setting authority to regulate toxic materials and harmful physical agents by setting parameters for this criterion (Appendix I expands on this and provides a table of cases decided under this precedent). The decision requires the agency to demonstrate a present risk and estimate the risk reduction the proposed standard would achieve. Practically, the benzene decision defines a set whose elements are the later decided cases (11/13 of which upheld OSHA either wholly or in significant part.) whose successful risk management analyses constitute a reference group of judicially sanctioned risk management approaches.

Since OSHA has just issued a revised version of the HCS [FR, 2012a; CFR, 2012d] that significantly alters the chemical hazard determination process, it seems a particularly appropriate time to consider the effectiveness of the former version.

\section{THE ORIGINAL STANDARD}

The original health hazard determination process had several "bright line" requirements. First, a floor of chemicals considered hazardous was specified, at one of two levels of specificity. For carcinogens, the presence of the chemical on one of two lists or its regulation by OSHA as a carcinogen was sufficient to identify the chemical as both hazardous and as a carcinogen or potential carcinogen [FR, 1983a, 1987a]. As of August, 2010, 414 agents in the three covered categories of carcinogens were listed in the largest of the three lists, produced by the International Agency for Research on Cancer using expert panels that weighed the strength of the scientific studies [IARC, 2011]. One hundred seven agents were listed as carcinogenic for humans (Group 1, a causal relationship has been established, with rare exceptions as to the type and amount of data required), 58 as probably carcinogenic to humans (Group 2A-limited human data plus causal animal data, again with rare exceptions) and 249 agents as possibly carcinogenic in humans (Group 2Blimited human with limited animal or causal animal data with inadequate human data). Except for a very few processes, the 414 chemicals listed have unique Chemical Abstracts Numbers, and were covered in mixtures as well (as of April, 2013, the total was 450).

Agents in the first two IARC groups (165) were to be labeled as carcinogens with the same designation carried onto the MSDS [OSHA, 1988]. For the third group, designation as a carcinogen was not required on the label, but the MSDS had to include such information.

The second list of carcinogens, created and maintained by the National Toxicology Program [NTP, 2011] contains 240 chemicals, with some overlap with the IARC lists [IARC, 2011]. These chemicals also had to be labeled as carcinogens under the cited Compliance Guidelines [OSHA, 1988].

Chemicals that appear on two other lists were treated as hazardous but the particular hazard(s) involved was left to the manufacturer or importer to determine [FR, 1983a, 1987b]. In the largest of these lists, that developed and maintained by the 
American Conference of Governmental Industrial Hygienists, there are currently some 700 chemicals, including chemical carcinogens [ACGIH, 2009].

\section{METHODS}

The databases used in the present report are available on the internet and are in the public domain.

The first database used in this report is the federal Bureau of Labor Statistics (BLS) annual Survey of Occupational Injuries and Illnesses (SOII) [BLS, 2013]. The BLS has provided incidence data on all work injuries/illnesses since 1972. In 1976 BLS added counts of work injuries/illnesses by injury characteristic for DAFW cases using the Supplementary Data System, coding cases from as many as 31 state workers' compensation systems who met the state's DAFW eligibility requirement for wage compensation. However, BLS concluded that "...national aggregation of State data [was]...problematic [Abraham et al., 1996]" because of stateto-state variability in case ascertainment and eligibility criteria. Consequently BLS shifted to incidence data by injury characteristics (nature, part, source, and event for the injury) for DAFW cases in 1992 by adding the required data elements to the nationwide incidence data survey of OSHA workplace injury logs [Abraham et al., 1996]. Before/after comparisons of the impact of the HCS on DAFW injuries attributable to hazardous chemical exposures are unavailable because the two standards were effective before injury characteristic data were available on a national level.

Incidence rates per 10,000 full-time equivalent employees (FTE) for injury characteristics for DAFW cases were standardized in 1992 with the introduction of the Occupational Injury and Illness Classification Manual (OIICM) [BLS, 2007]. The present report compares trends in private industry acute DAFW injuries and illnesses attributed to exposure events involving caustic, noxious or allergenic (CNA) substances (OIICM Injury Event code $34^{*}$, except $343^{*}$-injections, stings, venomous bites) with those for injuries/illnesses due to all other events (All other injuries' rates are treated as background - see below). CNA exposure events in 2007, for example, totaled 22,020 cases coded to chemical exposure events. Included in this total were 14,850 specific chemical source injuries and 6,520 All other sources chemical exposure events where the specific source was unidentified (unspecified and nonclassifiable sources). Together, these two codes constitute some 97\% of CNA exposure event cases) [BLS, 2009a] so chemical event exposure events with unspecified sources were combined with those for which a specific chemical exposure source was specified. In contrast, OSHA relied on the 17,340 cases coded to chemical sources in its revision, of which 15,750 were coded to chemical groups [FR, 2012b; BLS, 2009b]. While OSHA's 1983 and 1987 projection of cases avoided because of the HCS used LWD rates (DAFW + job restriction/transfer cases), injury event information has been available only for DAFW cases and so is used here.

The paper treats the period $1992-2009$ as a single period for analytic purposes. Choice of this study period presents three methodologic issues. The first is whether coding changes in the OIICM during the period created discontinuities in the data categorization. While there were some changes in the coding of chemical exposure events in 2007 [BLS, 2007], at the 3- and 4-digit levels, review of data in these categories for the period 2005-2008 reveals only small and inconsistent effects of these changes at the 2 and 3 digit coding levels.

The second issue is whether there have been changes in OSHA injury/illness recordkeeping that would affect the type of injury/illness reported to BLS. Friedman and Forst [2007] reported that OSHA's 1997 decision to obtain data directly by mail or other remote transmittal method [FR, 1997] but without any change in the definition of a work-related injury, did not produce a significant change in the BLS rate trend for lost workday cases during the period 1992-2001, using an earlier version of the JoinPoint methodology used in this report.

OSHA changed the type of injuries/illnesses that were to be recorded effective January 1, 2002. OSHA concluded that the various changes would offset each other so that "approximately the same number of injuries and illnesses will be recorded under the final rule as were recorded under the former rule [FR, 2001]." OSHA subsequently advised that "employers should use reasonable caution when comparing data produced by the old 1904 regulation with data produced under the new rule [OSHA, 2004]." BLS, however, has consistently taken the position that estimates from 2002 "are not comparable with those from previous years [BLS, 2002]."

The third methodologic issue involves the shift from the 1987 standard industrial classification (SIC) to the 2002 North American industry classification system (NAICS) in 2003 [BLS, 2003]. While BLS advises against comparisons of industry groups before and after the shift, there would appear to be no impediment to comparison of total rates so long as the rates are compared across all industries. The problematic area is whether changes in classification in the manufacturing and non-manufacturing sectors produced changes in the trendlines for the CNA categories.

Resolving the issue of whether BLS data can be used over the entire period 1992-2009 or must be restricted to the separate intervals 1992-2001 and 2003-2009 is critical to the design of the current study. The JoinPoint methodology used to estimate the association of the HCS with injury/illness rate trends ties the maximum number of trendlines that can be identified within a study interval to the number of years of data available for analysis [NCI, 2013a,b].

The National Cancer Institute's JoinPoint software (v. 3.5.4, August, 2012; and v. 4.0.4, May, 2013) [NCI, 2013a; 
Kim et al., 2000] for trend analysis is used. Beginning with an assumption that the rate of change is constant over the study period (a single slope), the software uses piecewise weighted least squares regression to identify the best fitting point(s), if any, at which there is a statistically significant change in the trend of incidence or mortality rates. The point at which any such change occurs is called a JoinPoint. The software provides the annual percent change (APC) in the interval defined by successive JoinPoints or between JoinPoints and the beginning or end rate entries. An average annual percent change (AAPC) over the entire study period represents the weighted average of the APCs, with weights equal to the length of the APC intervals. The software also provides a subroutine that was used to evaluate the trend data for coincidence and parallelism [NCI, 2013b; Kim et al., 2004] by injury type and industry group.

The model provides two computational methods, grid and Hudson's methods, the latter more intensive. In addition, each of the computational methods can be used with one of three models - permutation, Bayesian Information Criterion (BIC), and the modified BIC - for assessing the statistical significance of identified JoinPoints. Since there are differences in the sensitivity of the three models [Kim et al., 2000] and their ability to predict expected numbers of cases [Chen et al., 2012] the report gives results for all six computation method/model combinations.

Following current recommendation [Rothman et al., 2008] and practice [Schoen et al., 2012], natural log of rates were assumed to have heteroscedastic errors with Poisson variance.

JoinPoint software was first used to evaluate whether significant changes in rates coincided with the coding changes discussed. Then the software was used to estimate the reduction in the number of chemical event injuries/ illnesses associated with the HCS. FTE employed populations-at-risk were obtained by backing them out of the BLS DAFW injury/illness rates and the total case counts. All analytic runs used the log transform of the dependent variable, the crude rate for DAFW injuries/illnesses as the dependent variable assuming a Poisson variance, a Type I error of 0.05 , an uncorrelated errors model and evaluated up to three JoinPoints as recommended for study interval length.

BLS indicated that approximately 60,000 of the 250,000 establishments in the annual sample have been sampled repeatedly because of requirements for comprehensive industry and establishment subgroup inclusion (Personal communication, John Ruser, Ph.D., Assistant Commissioner for Occupational Safety and Health Statistics, October 18, 2011). Accordingly, sensitivity analyses were run fitting a correlated errors model with the correlation set at $0.1,0.2$, 0.25 , and 0.3 .

APCs and AAPCs from the JoinPoint analysis were used to estimate the reduction in the number of CNA injuries/ illnesses associated with the HCS. Lower and upper bound estimates were obtained by treating the HCS, first, as a marginal effect superimposed on the preventive effects of all other factors influencing workplace safety and health (background rate) and then, second, as the sole agent associated with any reduction in cases. Beginning with the second year of the study interval the percent change in the rate for the mutually exclusive categories of All other or CNA injuries/illnesses was subtracted from one to yield the percent of remaining or residual causes (RCP) responsible for the observed number of cases. No estimate of the reduction in cases is available for the first study year because no national information is available for the percent reduction from the year preceding the study interval.

Then, the RCP for each year was multiplied by the product of the $\mathrm{RCP}(\mathrm{s})$ for the preceding year(s) beginning with the RCP for the second year to track the cumulative impact. In notation, to 18

$\mathrm{RCP}_{k}=1-\mathrm{APC}_{k}$ for each study year $k$ where $k$ goes from 2

$\mathrm{CRCP}_{k}=\prod_{2}{ }^{k}(\mathrm{RPC})_{\mathrm{k}}$

RCP and CRCP borrow from the concept of attributable risk.

The approach and the detail in the available data do not permit teasing out the influence of specific factors on the background rate. There are many such factors such as the OSHA regulatory structure resulting from OSHA's implementation of its statutory duties by its promulgation of enforceable health and safety standards other than the HCS [Code, 2011a,b,c] and the Agency's ongoing interpretation of the employers' general duty obligations [Code, 2011d]. In addition, the criteria employed to select establishments for scheduled inspections [Code, 2011e] and its conduct of complaint inspections [Code, 2011f] have the potential to influence rates as does Congress' annual funding for such enforcement activities. Non-OSHA factors may include workers' compensation laws' and insurance companies' requirements, senior management health and safety attitudes and such social/demographic factors as the impact of recessions and deindustrialization on the composition of the workforce.

The analyses are done separately for manufacturing (SIC Division D groups 20-39 or NAICS sector codes 31-33) and nonmanufacturing industries (all other codes). Since the Hudson method can identify a change in an APC during a study year, an unweighted average of the two APCs effective during the year was used when an approximate mid-year shift was present.

The annual observed number of CNA cases is divided by the CRCP for that year to obtain the number of CNA injury/ illness cases that would have been expected. The result is subtracted from each year's observed number to estimate either the background trendline effect or the trendline effect associated with CNA injuries/illnesses. The difference between the two cumulative sums is used as the lower 
bound estimate for the impact of the HCS. Note that adjusting each year's observed injury count provides some degree of adjustment for changes in OSHA such as shifts in inspection strategies or deindustrialization events such as the decline in manufacturing or overseas outsourcing of high risk jobs to the extent such factors affect the observed counts.

The second scenario treats the HCS as the sole factor in the decrease of CNA injuries by using only the sum of the difference between the observed and expected case numbers for each year based on the CRCPs for the trends for CNA injuries. This approach recognizes that many OSHA standards such as those governing lockout/tagout procedures for electrical operations [CFR, 2012e] or protective procedures for guarding openings during building construction [CFR, 2012f] have, at best, a highly attenuated connection to chemical exposure events.

If the HCS had no effect, then the rate curves within each industry group would be expected to be parallel.

The second databases used are the annual files of the Toxic Release Inventory (TRI) maintained by the Environmental Protection Agency. The law requires that each covered facility annually report the amounts of toxic chemicals released on-site and consumed on-site [Code, 2011g; EPA, 2013a]. EPA's Tri Explorer [EPA, 2013b] software identifies manufacturing facilities (SIC Division D groups 20-39 or NAICS sector codes 31-33) in the "core industries" that have been required to submit release information for each year since the requirement was implemented in 1987. Similarly, the software permits identification of a "core set of chemicals" and core "OSHA carcinogens" for which reporting has been required since 1988 [Code, 2011h; EPA, 2013b]. TRI's list of 1988 OSHA carcinogens comprise a subset of some 180 OSHA covered carcinogens [EPA, 2005], though the number of carcinogens for which releases are reported in any given year is in the range 100-125 (data for 1988, 1996, 1999, 2004, and 2009).

Total releases and the number of reporting facilities are compared for two groups by graphing the releases on semilog paper to evaluate the association with the HCS for the period 1988-2009. The two study groups include a case group of 10 organic chemicals classified as IARC 1 or $2 \mathrm{~A}$ carcinogens or as NTP carcinogens whose exposure limits are specified on the outdated Tables Z-1 and Z-2 [CFR, 2012c], not by individual standards. Cases were compared with an unmatched control group of 12 very hazardous organic chemicals as measured by PELs of $\leq 25 \mathrm{ppm}$.

The carcinogens selected for the case group have required a "carcinogen warning" on the label [OSHA, 1988], while for the control group relatively non-specific hazard warning such as "lung damage" suffice. Case and control chemicals were included if total combined facility releases were $\geq 100,000 \mathrm{lbs} /$ year for each of the 22 reporting years 1988-2009 and, with rare exceptions, at least 20 facilities reported releases each year. Metal carcinogens such as chromium VI were excluded because reports of releases of covered metal compounds do not distinguish valence states, for example, chromium VI and chromium III [EPA, 2004]. Control chemicals did not include any chemical classified by IARC as $2 \mathrm{~B}$. Eight of the 10 case chemicals and 10 of the 12 control chemicals are also covered by additional EPA regulations [EPA, 2010].

To assess whether changes in annual releases reflected fluctuations in the combined total of the chemical produced in the United States or imported (referred to as usage) annual usage levels were cobbled together from sporadic reports [NTP, 2011; NLM, 2012; CEN, various; CMR, various]. Reported usage was compared for consistency with quadrennial data in EPA's Inventory Update Reporting [EPA, 2013c] required by the Toxic Substances Control Act [Code, 2011i]. Usage was analyzed if usage values were consistent with at least four of six EPA reports.

\section{RESULTS}

In the 168 of 216 combinations where a JoinPoint could have been identified (excluding the first 2 and last 2 years using the methodology's default option for initial and terminal subinterval length), there were 22 JoinPoints found (4 in manufacturing, 18 in nonmanufacturing industries), excluding the interpolated values resulting from intra-study year APC changes. Of these, only five JoinPoints occurred in 2002 or 2003, inconsistently across the method/model combinations (Table I). This result yields no support for BLS' position that post- and pre-2002 comparisons are impermissible.

All 46 APCs in all computation method/model combinations (including the 24 study start intervals) are negative and document a continuous decline in incidence rates over all study sub-intervals for both the CNA and All other injuries groups. The 12 initial APCs for manufacturing industries involving the first year of the study interval are significant for all computation/model combinations while in the nonmanufacturing industries nine of twelve are significant. For the three non-significant APCs (all less than -3\%), APCs beginning 2 years later with the same method are large and significant. Five of six percent differences between AAPCs for CNA injuries/illnesses and All other injuries/illnesses are greater in manufacturing than the comparable differences in nonmanufacturing industries.

In manufacturing industries, where the standard effective data preceded the availability of injury characteristic data by a decade, the APCs for CNA injuries/illnesses exceeded those for All other injuries in all years in three of six models (grid/ modified BIC, Hudson's/permutation, and Hudson's/modified BIC). In the grid/BIC method, there was a 4-year interval (2004-2007) in which the CNA rate was stable with a nearly zero APC. This stability coincided with a period in which 


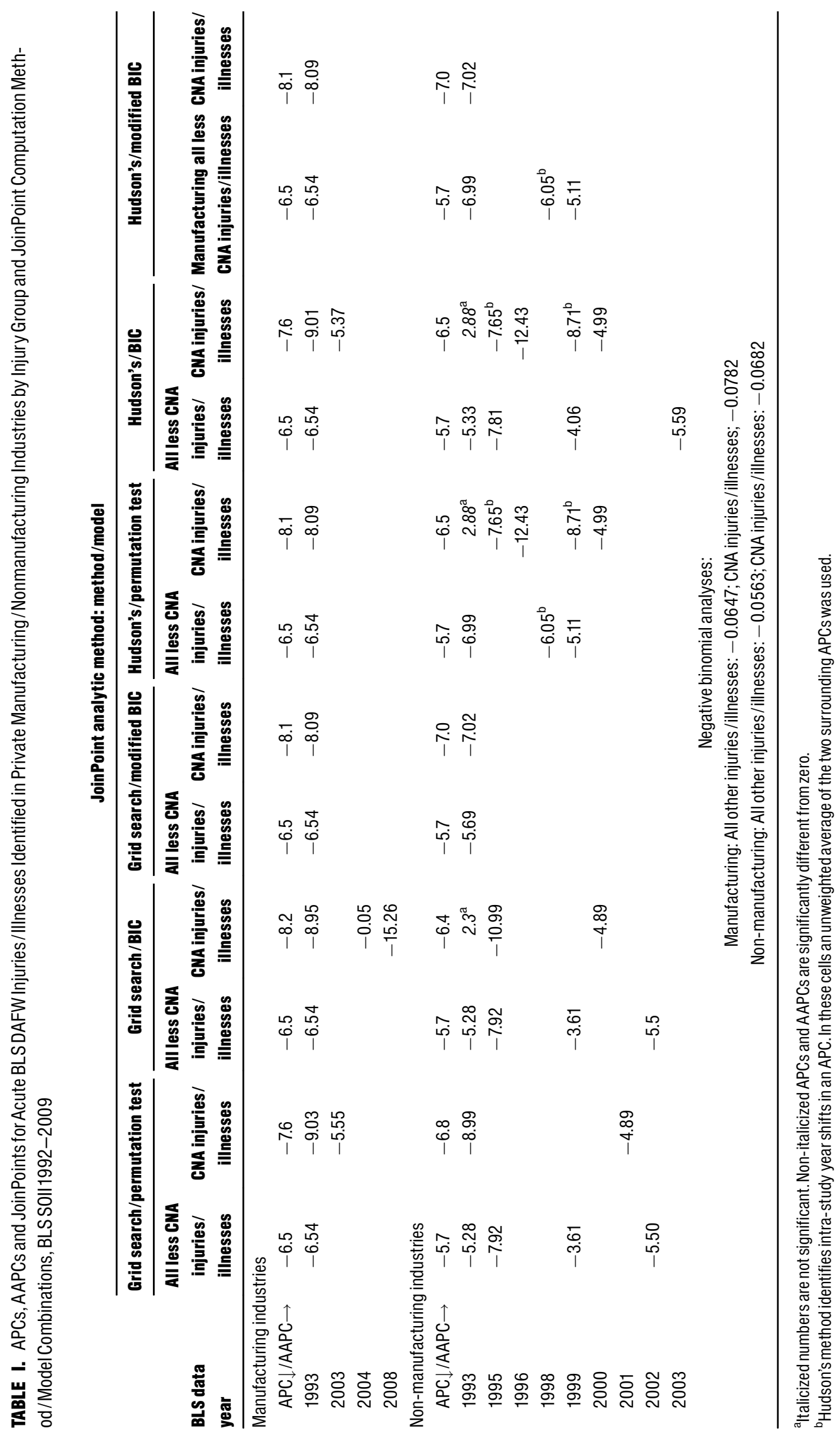


manufacturing jobs remained stable before beginning a large decline that was associated with a much larger negative APC. With the onset of the most recent recession this single model produced a strikingly large increase in the negative APC to -15.26. In the grid search and Hudson's/BIC combinations there is a suggestion that the marginal HCS effect may have been lost later in the study period. All of the grid method/ model combinations reject parallelism $(P \leq 0.03$; parallel test unavailable for Hudson's method combinations).

In nonmanufacturing industries the patterns are more complex. The AAPCs for CNA injuries/illnesses are greater for all models although subinterval APCs are not significant in three models until 2 years into the study interval. Again, all of the grid method/model combinations reject parallelism $(P<0.01)$

Table II shows the methodology applied to calculate by calendar year the reduction in the number of CNA injury/ illness DAFW cases associated with the HCS in nonmanufacturing industries. Results are shown for the grid search/ permutation model and Hudson's method/modified BIC because the former is most frequently reported while the latter has been identified as most accurate in predicting future cases in a recent report [Chen et al., 2012]. Overall, considering the HCS effect as a marginal effect, the grid method/permutation test model estimates a reduction of 130,217 cases (line 1, bottom) with an additional 41,814 case difference in the manufacturing industries for a total marginal effect decrease of 172,031 cases. If the HCS is treated as the sole basis (Scenario 2) for the reduction in CNA injuries/illnesses, then the case count was reduced by 523,492 cases (line 5, bottom) during the 18 -year study interval. While the Hudson/modified BIC combination estimates substantially fewer nonmanufacturing cases than the grid/permutation as a marginal effect total (line 3 ) the sole effect estimate total is within approximately $10 \%$ of the larger number for the grid/permutation combination.

Table III shows the estimates of the reduction in cases provided by the various JoinPoint computation method/ model combinations and the result from a negative binomial regression for the entire study period (less restrictive variance estimator). When the HCS effect is treated as a marginal effect five of six estimates are reasonably close $(96,909$ $123,545)$, with the grid/permutation combination the group outlier $(172,031)$. If the estimates reflect only the effect of the HCS APCs then once again the grid/permutation is the outlier and the remaining estimated reductions range from 458,410 to 466,118 . The differences between the totals under the marginal effect approach largely reflect effects in the nonmanufacturing industries (Table II).

When regression predicted annual rates are use to compute a new set of "observed" cases, the results are very close to those with the actual observed numbers. Sensitivity analyses with 0.2 autocorrelation because of repeated sampling of firms in some industry subgroups are similar to those from the combinations in which no autocorrelation is included, suggesting that repeated yearly sampling of a subsample of establishments in some industries produces no detectable correlation of injury counts.

Similarly, the use of AAPCs or the single annual percent changes derived from negative binomial analyses also yield estimates within the range of estimates from JoinPoint computation method/model combinations. While the use of the average percent change and the negative binomial APCs yield useful information on the estimated reduction in the number of cases they provide no potential additional mechanism to tie such changes to the introduction of workplace changes during a study interval.

Figure 1 compares the combined total facility releases for the carcinogenic chemicals with the highly toxic noncarcinogenic chemicals (case and control groups). Semi-log paper is used to highlight the rate of decline over the 22-year study period. In part B, there is a single value off the graph for total releases (1988 total releases for carbon disulfide of $124,264,714$ pounds).

Among the carcinogenic chemicals (part A) 7 of 10 chemicals show a substantial drop in total releases, generally of an order of magnitude or greater (1988 was the fifth full year of its application to manufacturing). Six of seven chemicals in this group were classified as 1 or $2 \mathrm{~A}$ carcinogens or listed by NTP before 1988 and tetrachloroethylene was listed in 1989 [NTP, 2011] (one, propylene oxide, was classified as 2A in 1987 [IARC, 1987], reclassified as 2B in 1994 [IARC, 1994] but listed by NTP in its 1991 report [NTP, 2011]). Only one of the seven, trichloroethylene, was classified by IARC later (1995) [IARC, 1995] but its release history may have been tied to control measures for tetrachloroethylene. The other three chemicals show no effects that could be related to the HCS.

In contrast to the dominant pattern for carcinogens, only one (carbon disulfide) of 12 non-carcinogens with low OSHA PELs (part B) shows a comparable order of magnitude decline similar to the seven carcinogens, four show moderate declines, while seven chemicals in this group show either a minimal decline or show wide swings over the interval.

In terms of facilities reporting releases for chemicals in the two groups, the facility pattern mimics the pattern for carcinogen releases, though the drop in facilities reporting usage for carcinogens is much less striking. There is little to suggest any decline in the number of reporting facilities for non-carcinogen toxics.

Data adequate for usage determination were available for seven carcinogens and five non-carcinogens. Four chemicals had usage of greater than one billion pounds for all, or nearly all, of the quadrennial reports. One was a carcinogen (propylene oxide) and three were non-carcinogens (aniline, phthalic anhydride and phenol). Propylene oxide had usage as high as 3.5 billion pounds annually toward the end of the study interval starting at some 2.5 billion pounds (phenol was the only noncarcinogen higher, increasing from 3 to 4.5 billion). Propylene oxide had a rapid decline in releases while 


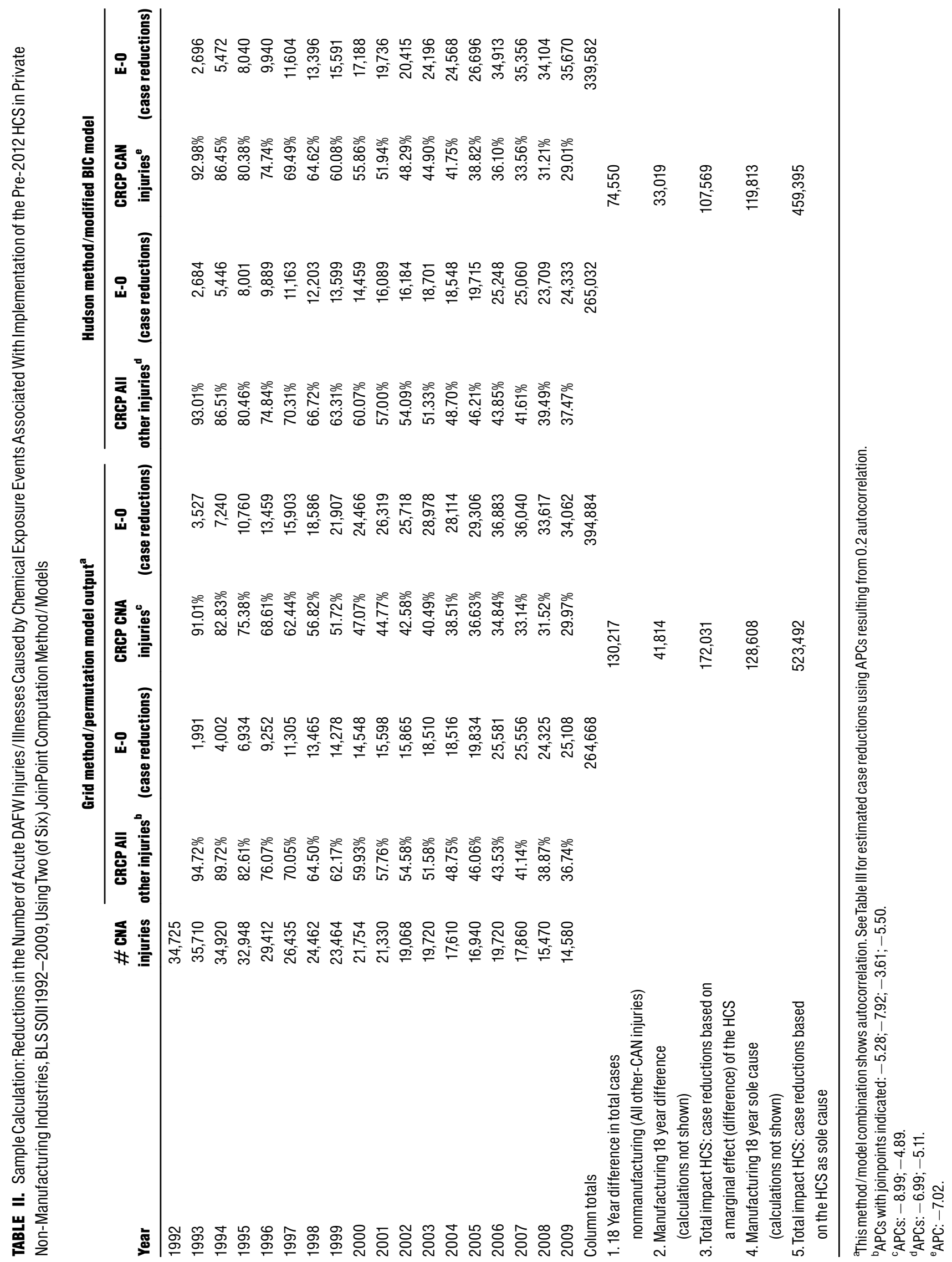


TABLE III. Summary Estimates of Reductions in the Number of Acute DAFW Injuries/llnesses Caused by Chemical Exposure Events in Private Industry Groups Associated With Implementation of the Pre-2012 HCS Standard Using JoinPoint Estimating Methodologies and the Negative Binomial Model, BLS SOII1992-2009

\begin{tabular}{|c|c|c|}
\hline Method/model combinations & $\begin{array}{l}\text { Based on differences between impact of } \\
\text { All other injury factors and CNA injury factors, } \\
\text { each curve impact computed separately }\end{array}$ & $\begin{array}{l}\text { Based on yearly APCs for } \\
\text { CNA injuries/illnesses only }\end{array}$ \\
\hline Grid method/permutation test model & 172,031 & 523,492 \\
\hline Hudson method/permutation test model & 96,909 & 458,410 \\
\hline Grid method/BIC model & 112,689 & 464,150 \\
\hline Hudson method/BIC model & 114,691 & 466,118 \\
\hline Grid method/modified BIC model & 123,545 & 459,395 \\
\hline Hudson method/modified BIC model & 107,569 & 459,395 \\
\hline \multicolumn{3}{|l|}{ Sensitivity analysis with autocorrelation set at $0.2^{\mathrm{a}}$} \\
\hline $\begin{array}{l}\text { Grid method/permutation test model } \\
\text { ( } 2 / 4 \text { analyses showed fewer APCs but } \\
\text { with the AAPC little affected) }\end{array}$ & 153,188 & 514,462 \\
\hline $\begin{array}{l}\text { Grid method/BIC model ( } 1 / 4 \text { analyses, } \\
\text { different method/model than preceding, } \\
\text { showed larger APCs with the JoinPoints } \\
\text { shifted } 1 \text { year and the same AAPC) }\end{array}$ & 113,778 & 465,240 \\
\hline Grid method/modified BIC model & 107,569 & 459,395 \\
\hline \multicolumn{3}{|l|}{ Using the average annual percent change from JoinPoint } \\
\hline Grid method/permutation test model & $96,365(107,774)^{b}$ & $432,068(443,477)^{b}$ \\
\hline Hudson’s method/modified BIC model & 122,438 & 458,141 \\
\hline $\begin{array}{l}\text { Using the percent annual change from a negative } \\
\text { binomial model (one value for the entire study period } \\
\text { for each industry group) }\end{array}$ & 107,639 & 438,442 \\
\hline
\end{tabular}

${ }^{a}$ Autocorrelation option unavailable with Hudson's method.

${ }^{\mathrm{b}}$ Figure in parenthesis uses APC from autocorrelation set at 0.2 .

the non-carcinogens had a much slower decline or, in the case of phthalic anhydride, an erratic decline. Four carcinogens and one noncarcinogen had usages of between 100 million and one billion pounds with increasing usages over the study. Three of the four carcinogens had steep rates of decline in releases (chloroform, tetrachloroethylene, and di(2-ethylhexyl)phthalate). The non-carcinogen (maleic anhydride) rate of decline was much slower than the decline for chloroform although chloroform had a much higher percent increase in usage starting from roughly the same baseline. Three chemicals showed declines in usage with the rate of decline tracking usage for two, carbon tetrachloride (carcinogen) and carbon disulfide, (noncarcinogen).

\section{DISCUSSION}

\section{Methodology}

\section{Record-keeping and coding changes}

BLS' insistence that changes in work injury/illness reporting and OIICM coding changes preclude comparison of
SOII data before and after 2002/2003 is unsupported in the present analysis. Moreover, BLS has announced that coding changes effective with 2011 data [BLS, 2011] will once again truncate available data sets. BLS' position would yield three separate analytic periods for injury characteristic data: 1992 2001, 2002/2003-2010, 2011+.

The continued truncation of data comparability limits the widespread application of trendline analysis, particularly at the more detailed occupation and industry levels where associations between work practices and work injuries would be clearer. Truncation does so because JoinPoint specifies the maximum number of JoinPoints for an analysis based on the length of the study interval for example, 1 for a 10 -year interval but three for an interval of 20 years to a maximum of five for 27+ years [NCI, 2013b].

For comparison, a study of trends in specific causes of death for study periods as long as 75 years are possible because of standard practice with the International Classification of Disease (ICD) [CDC, 2011] used to code mortality. Comparability studies, also referred to as bridge-coding or crosswalk studies, have been standard with successive revisions of the ICD since at least the Fifth revision 

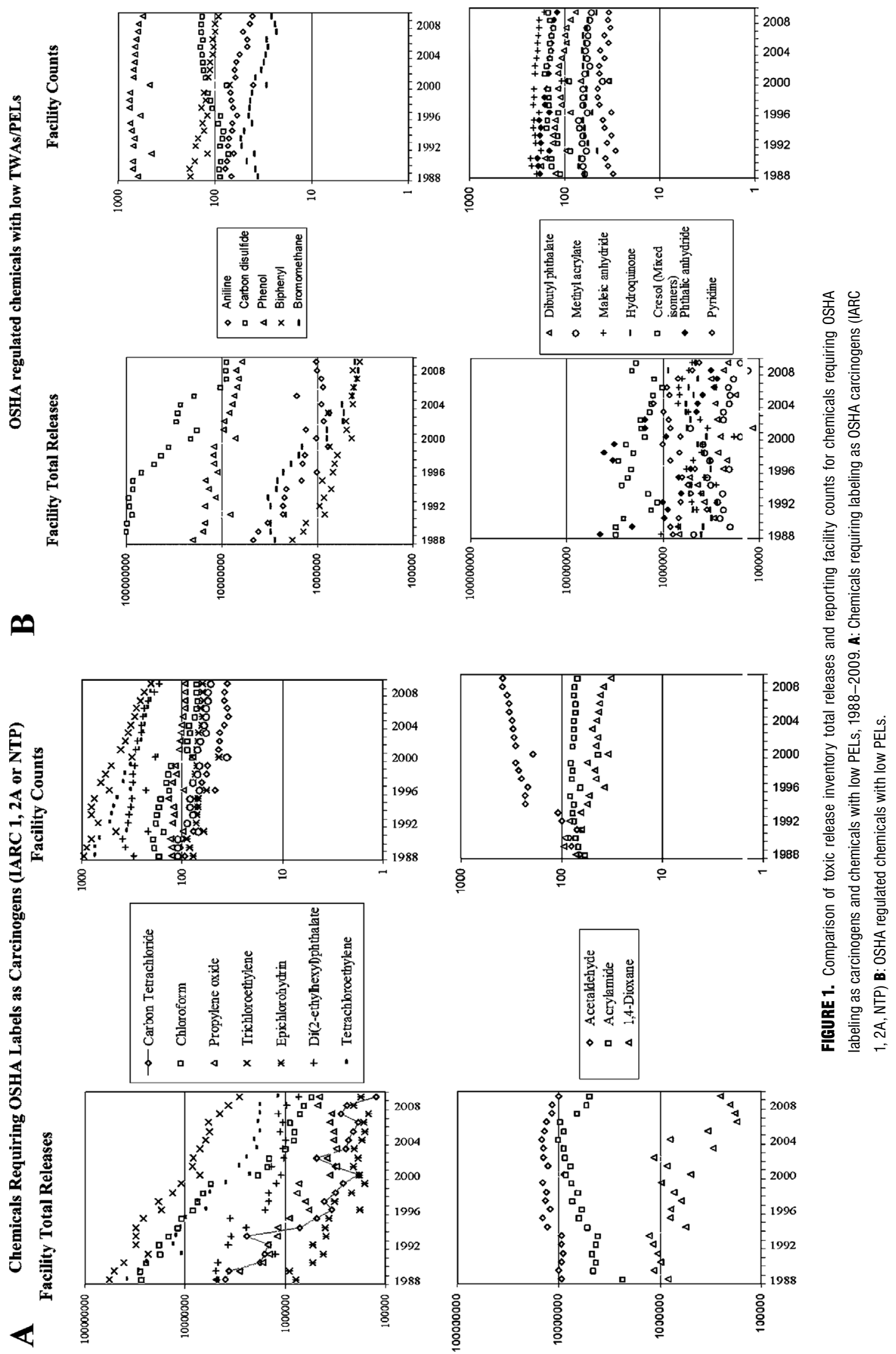
(1939-1948) [Anderson et al., 2001]. This type of study codes a sample of deaths both in the old and new code versions to yield comparability ratios for use with long-term studies. While BLS cites budgetary constraints as a reason for not doing such a study for the previous and present coding versions, a recent paper by Bertke et al. [2012] using data in 800 injury/illness narratives from the Ohio Bureau of Workers' Compensation reports using software for coding causation by the BLS coding scheme that results in an overall sensitivity of $84.1 \%$, varying by causation subcategory. With further investigation, this software might remove the financial impediment to a crosswalk study by BLS.

There is one further note on BLS methodology. In 2011, BLS [2011b] reported that an input error had resulted in a $0.7 \%$ overstatement of all SOII recordable cases (DAFW plus non-DAFW cases) in the 2007-2009 data but concluded that the effect on the national counts of DAFW cases was small and did not revise published numbers.

\section{JoinPoint piecewise regression analysis}

Since its release in 1998 [NCI, 2013b], the methodology has been extensively used to identify etiologies for changes in APCs over time in various illnesses. A keyword search on Ovid MEDLINE (November, 2011: keyword searches words involve the title, abstract and subject heading) yielded 324 articles. Approximately $75 \%$ of listed articles were available online through the University's online service. A systematic, non-random sample of 33 articles published during the period 2007-2011 showed that 31/33 used the methodology to correlate the years in which changes in the APC(s) occurred with possible explanations for such changes, for example, the prostate specific antigen blood test and the incidence of prostate cancer [Kim et al., 2000]. Several sampled studies using the JoinPoint methodology estimated the impact of the APC changes on case counts [Cowling and Yang, 2010; Arfe et al., 2011].

The present data indicate that it may be unwise to rely on a single computation method/model combination to estimate the reduction in the number of injuries/illnesses, particularly since the default method, the grid method/permutation combination, yielded the outlier estimate in this data set. A recent report [Chen et al., 2012] found that "among the models that were compared [including both the permutation and modified BIC models], the JoinPoint regression model with modified Bayesian Information Criterion selection produced estimates for the near future that are "closest to actual number of [cancer] deaths" As a result this combination is to be employed by the American Cancer Society to project future near-term cancer deaths.

The choice of data analysis scenarios also affects the substantive results. A third scenario was considered, but ultimately rejected as overly conservative. This scenario used the annual difference between the APCs for All other injuries/illnesses and those for the CNA injuries/illnesses to calculate the RCPs and CRCPs used to estimate the expected numbers of injuries. When this was done, the lower bound estimates were $40-50 \%(42,230-86,009)$ of those reported for the grid search/permutation method and modified BIC/ Hudson's method by the first analytic scenario. The scenario was rejected because it likely overemphasizes the effect of new OSHA initiatives on the "background" rate compared to the evolving effect of the single standard from its implementation date. This third scenario would have no effect on the upper-bound estimate.

\section{Substantive Results}

The results for the BLS SOII data and the EPA TRI data are consistent by pointing in the same direction. The JoinPoint methodology strongly suggests that the HCS has been associated with an estimated decline in 107,569459,395 acute DAFW cases (permutation method/modified BIC model) due to chemical exposure events during the follow-up period of 1992-2009, using the more conservative of the scenarios reported. The EPA data document a reduction in releases of the harmful agents studied, particularly carcinogens, that is viewed as a proxy for workplace exposure in this study. While identifying a JoinPoint at, or within a reasonable latency period, following industry-wide implementation would have provided additional evidence of the association, nationwide data were available only beginning in 1992.

The estimate issued with the original standard was based upon was then the "best available evidence [Code, 2011a]," as required by the statute. The present study shows that OSHA'S 1983 estimate [FR, 1983b] for manufacturing of a $20 \%$ cumulative reduction in the CNA injury/illness rate over the first 20 years of the HCS standard substantially underestimated the actual percent decline even under the conservative scenario. While a comparable cumulative reduction was seen in nonmanufacturing industries over the study period, the decrease did not occur immediately in 1987 as predicted by OSHA [1987].

Given the recent controversy over the issue of undercounting of DAFW injuries in the BLS SOII survey [Oleinick and Zaidman, 2004, 2010a,b; Boden and Ozonoff, 2008, 2010; Boden, 2013], could under-reporting in the various study groups explain all, or part, of the present results? The results of the recent simulation study of Bena et al. [2004] using Poisson regression and involving trends for workrelated fatalities are relevant to this issue. Under simulation conditions closest to the conditions seen in the present study, the bias in the trend estimate "shrinks to zero $[\leq 2.0 \%]$ " with one important exception. The "similar" conditions are survey employment size (CPS estimates of employment in the range of 10-25 million versus SOII estimates of the same or larger 
numbers of FTEs based on hours worked from the SOII survey of 230,000 establishments spread over five size classes), "true" fatality rates (a rate of 20/100,000 workers versus CNA rates of 19-91/100,000) and annual trend decreases of $6.4 \%$ (versus a maximum APC of -15.26).

The important exception involves a change in the proportion counted over time. The authors concluded that "[c]hanges in the undercounting of fatal injuries over time... causes [changes] in the trend bias." Unfortunately, there are no data on undercount changes over time in the SOII and only some data on changes in case ascertainment fractions over time at the national level is provided by OSHA's Data Initiative project (ODI) [ERG, 2009]. Begun in 1996, and substantially revised to its present form in 1998, the ODI uses a review of the log, employee records and employee interviews to monitor the quality of data in the mandatory injury/illness logs that form the basis of the SOII. The sample of 250 establishments from 80,000 establishments in highhazard industries (except construction) provides an “... acceptable level of power for detecting overall accuracy of employer recordkeeping at-or-above a 95\% threshold." The percentage of audited establishments meeting this criterion for all types of work injury/illness cases has been in the range $90-96 \%$ in the calendar period 1998-2006 in no apparent temporal pattern. While the survey is too small to provide statistically reliable data for DAFW cases, the summary raw data do not show any trend in the undercounting fraction in the period 1998-2006. Better resolution of this important methodologic issue must await better data.

There are limited data that indicate that the much more expansive upper bound estimate using the APCs for CNA injuries/illnesses alone to predict the reduction in cases is too high and masks the effect of other variables. Haviland et al. [2010] found that OSHA inspections resulting in a citation produced a cumulative reduction in Pennsylvania workers' compensation injury rates of $8.2-14.4 \%$ over the following 2 years in single facility manufacturing establishments with 20-250 employees. However, only $1 / 3$ rd of such facilities had an OSHA inspection during the study period while the fraction cited was unstated. An earlier study by the same group [Mendeloff and Gray, 2005] using BLS SOII data found similar results although the fraction of establishments inspected was considerably smaller. Nelson et al. [1997] reported that compensable fall injuries decreased from 1.78 to 1.39 per $200,000 \mathrm{hr}$ worked (=100 FTE) in the years before and after an inspection citation compared to a decrease from 1.04 to 0.95 in employers that were not cited. In their study $5.6 \%$ of employers insured by the state workers' compensation fund were inspected and cited for violation of the fall standard. In a later study from the same group, Baggs et al. [2003] also reported a drop in compensation claims in the year following inspection citations: of approximately $22 \%$ (significant) for employers with fixed sites (e.g., agriculture, manufacturing) who underwent enforcement visits compared to a $7-8 \%$ decrease in those without enforcement visits. A comparable decrease occurred among employers with nonfixed sites, such as construction, but it was not significant. These data suggest that using only the rate changes for CNA exposure events to estimate the impact of the HCS produces an overestimate and underlines the necessity of controlling for the background rate.

The tables and figures also do not include data on explosion or fire events with the source attributed to chemicals. The numbers are quite small, with a maximum number of injuries/illnesses due to this event of 704 in 1993. A 5-year moving average of OIICM major category 5 (fires and explosions) fell from an average of 500 cases in the period 1992-1996 to 212 in the period 2005-2009 [BLS, 2009a].

A reason that the lower bound estimate likely understates the reduction in cases is that the analysis only considered private industry DAFW cases. Beginning in 2008, BLS included state and local government cases in its annual news release [BLS, 2009c]. A review of the numbers for 20082011 showed that private industry DAFW cases constituted $75-80 \%$ of total DAFW cases. If the trends in private industry and state and local government were comparable for All other injuries and CNA injuries, study estimates would increase.

Could the rise (1992-2001) and plateau (2002-2009) [Ruser and Wiatrowski, 2013] in the percent of lost workday cases (DAFW + job transfer/job restriction) represented by job transfer/job restriction cases without DAFW explain the study's findings? For the reasons laid out in Appendix 2 with tables (online), this explanation does not appear to explain the results for the period 1992-2009.

Could business cycle events explain the study findings? There were three recessions during the study period: July, 1990 to March, 1991; March, 2001 to November, 2001 and December, 2007 to June, 2009 [BLS, 2010]. Only the last two recessionary periods were all/largely contained in the study interval. Since a possible recession effect is evident in only one of the 24 JoinPoint analyses (grid search/BIC model 2008-2009 with APC -15.26) and the upper and lower bound estimates of case reductions associated with the HCS produced by this method are not different from the other computation method/models there is little evidence of a recession effect on either the lower or upper bound estimate. While the causes of unemployment in any recession are a complex mix of increased outflows from employment and reduced inflows to employment [Frazis and Ilg, 2009], the result is the same for the remaining workforce: either greater seniority in particular jobs or greater job experience in general (when the young worker cannot find a job) but this consequence appears not to have produced a detectable effect on model estimates.

Could the loss of manufacturing jobs overseas have contributed to study results? Employment in manufacturing 
fell by one third over the study interval. If the most unsafe workplaces were moved overseas, then fewer injuries/ illnesses might be observed in the affected years. However, the correction of the number of observed cases annually by the CRCP adjusted for the APC in the affected year would adjust for this possibility in large part because the observed number of acute work injuries/illnesses for both the All other and CNA injury/illness groups would already reflect the domestic retention of safer jobs.

In terms of carcinogens, the EPA TRI database indicates a sharp reduction in total chemical releases to the environment of a case group of OSHA carcinogens compared to a less dramatic reduction in a control group of noncarcinogens over the 22-year study interval, 1988-2009, with a similar but smaller decline in the number of facilities reporting the releases. Where direct comparisons of the releases of carcinogens and noncarcinogens are possible, taking usage into account, the carcinogens appear to a have a steeper rate of decline, although the data involve a small number of chemicals. OSHA anticipated [FR, 1983b] that employers might substitute less hazardous for more hazardous chemicals with the availability of the information mandated by the HCS. In a 1992 Briefing Report to Congress the General Accounting Office [GAO, 1992] reported the results of a 1990-1991 survey of employers of all sizes (only 2-3 years after the HCS became fully effective) that found $29 \%$ reported substitution of less hazardous chemicals. Thus, for some workers exposure was either eliminated completely by substitution or reduced by improved engineering controls. The more rapid decline in releases of carcinogens compared to toxic non-carcionogens and the more rapid decline in the number of establishments reporting any releases for carcinogens suggests that both corrective actions identified by GAO have occurred. It is likely that at least a portion of the more rapid decline in carcinogens reflects theeffect of information on the labels on improved engineering controls, reduced establishment usage and employee awareness.

\section{CONCLUSION}

The data indicate that OSHA's projected effectiveness of the previous version of its chemical Hazard Communication standard, accepted as meeting the Supreme Court'requirement for significant risk reduction by the Third Circuit, is consistent with the associations noted for chemical exposure events. The estimates of reductions in observed cases associated with the HCS suggest a significant health and preventive medicine impact. A determination of whether the present version will be as effective will require the availability of data comparable to that used in the present study but the failure of BLS to undertake comparability studies of its evolving injury/illness coding scheme will, by BLS' own assertion, prevent any such comparison.

\section{REFERENCES}

Abraham KG, Weber WL, Personick ME. 1996. Improvements in the BLS safety and health statistical system. Mon Labor Rev 119(4): 3-8.

American Conference Governmental of Industrial Hygienists (ACGIH). 2009. TLVs $\subset$ and BEIs $\subset$. (Based on the documentation of the Threshold Limit Values for chemical substances and physical agents \& Biological Exposure Indices). Cincinnati, OH: Signature Publications

AFL-CIO (AFL-CIO v. OSHA). 1992. 965 F2d. 962 (CA3).

Am Textile (American Textile Mfrs. v. Donovan). 1981. 452 U.S. 490, 506 n. 25 .

Anderson RN, Minino AM, Hoyert DL, Rosenberg HM. 2001. Comparability of cause of death between ICD-9 and ICD-10: Preliminary estimates. Natl Vital Stat Rep 49(2):1-32. http://www. cdc.gov/nchs/data/nvsr/nvsr49/nvsr49_02.pdf.

Arfe A, Malvezzi M, Bertuccio P, Decarli A, Vecchia CL, Negri E. 2011. Cancer mortality trend analysis in Italy, 1970-2007. Eur J Cancer Prev 20(5):364-374.

Baggs J, Silverstein B, Foley M. 2003. Workplace health and safety regulations: Impact of enforcement and consultation on workers' compensation claim rates in Washington State. Am J Ind Med 43:483494.

Bena JF, Bailer AJ, Loomis D, Richardson D, Marshall S. 2004. Effects of data limitations when modeling fatal occupational injury rates. Am J Ind Med 46:271-283.

Bertke SJ, Meyers AR, Wurzelbacher SJ, Bell J, Lampl ML, Robins D. 2012. Development and evaluation of a Naïve Bayesian model for coding causation of workers' compensation claims. J Saf Res 43(56):327-332.

Bureau of Statistics (BLS), Labor. 2002. Lost-worktime injuries and illnesses: Characteristics and resulting days away from work, 2002. http://www.bls.gov/iif/oshwc/osh/case/osnr0019.pdf.

Bureau of Labor Statistics (BLS). 2003. Lost-worktime injuries and illnesses: Characteristics and resulting days away from work, 2003. http://www.bls.gov/iif/oshwc/osh/case/osnr0022.pdf.

Bureau of Labor Statistics (BLS). 2007. Occupational illness and injury classification manual. Version 1.0 (1992 as revised). http://www.bls.gov/ iif/oiics_manual_2007.pdf.

Bureau of Labor Statistics (BLS). 2009a. Table R33. Number of nonfatal occupational injuries and illnesses involving days away from work by event or exposure leading to injury or illness and selected sources of injury or illness, 2007. http://www.bls.gov/iif/oshwc/osh/case/ostb1975. pdf (same table number previous reports)

Bureau of Labor Statistics (BLS). 2009b. Table R27. Number of nonfatal occupational injuries and illnesses involving days away from work by source of injury or illness and selected events or exposures leading to injury or illness, 2007. http://www.bls.gov/iif/oshwc/osh/case/ostb 1969.pdf.

Bureau of Labor Statistics (BLS). 2009c. Nonfatal occupational injuries and illnesses requiring days away from work, 2009. http://www.bls.gov/ news.release/archives/osh2_11092010.htm.

Bureau of Labor Statistics (BLS). 2010. Issues in Labor Statistics. Sizing up the 2007-2009 recession: Comparing two key labor market indicators with earlier downturns. Issues in Labor Statistics: December: Summary 10-11: 1-6. http://www.bls.gov/opub/ils/pdf/opbils88.pdf.

Bureau of Labor Statistics (BLS). 2011. Nonfatal injuries and illnesses requiring days away from work, 2011. http://www/bls.gov/news.release/ archives/osh2 11082012.pdf. 
Bureau of Labor Statistics (BLS). 2011b. Injuries, illnesses and fatalities. www.bls.gov/iif.

Bureau of Labor Statistics (BLS). 2013. Injuries, illnesses and fatalities: IIF Databases. http://www.bls.gov/iif/\#data.

Boden LI. 2013. Capture-recapture estimates of the undercount of workplace injuries and illnesses: Sensitivity analysis. Am J Ind Med (Early view)

Boden LI, Ozonoff A. 2008. Capture-recapture estimates of nonfatal workplace injuries and illnesses. Ann Epidemiol 18:500-506.

Boden LI, Ozonoff AI. 2010. Researcher judgment and study design: Challenges of using Administrative data. Am J Ind Med 53:37-41.

Canadian Centre Occupational for Safety Health (CCOSH). 2013. http:// ccinfoweb.ccohs.ca/rtecs/search.html.

Centers for Disease Control Prevention (CDC). 2011. International classification of diseases, 9 th revision. http://www.cdc.gov/nchs/icd.htm.

Chemical, Engineering News (CEN). Top 50 chemicals production ... (propylene oxide). Available at ProQuest, a commercial online database.

Code of Federal Regulations (CFR). 2012a. 29 C.F.R. 1910.1001 et seq. http://www.gpo.gov/fdsys/pkg/CFR-2012-title29-vol6/pdf/CFR-2012title29-vol6-part1910-subpartZ.pdf.

Code of Federal Regulations (CFR). 2012b. 29 C.F.R. 1910.119 http:// www.gpo.gov/fdsys/pkg/CFR-2012-title29-vol5/xml/CFR-2012-title29vol5-sec 1910-1119.xml.

Code of Federal Regulations (CFR). 2012c. 29 C.F.R. 1910.1000 http:// www.gpo.gov/fdsys/pkg/CFR-2012-title29-vol6/xml/CFR-2012-title29vol6-sec 1910-119.xml.

Code of Federal Regulations (CFR). 2012d. 29 C.F.R. 1910.1200 http:// www.gpo.gov/fdsys/pkg/CFR-2012-title29-vol6/xml/CFR-2012-title29vol6-sec 1910-1200.xml.

Code of Federal Regulations (CFR). 2012e. 29 C.F.R. 1910.147 http:// www.gpo.gov/fdsys/pkg/CFR-2012-title29-vol5/xml/CFR-2012-title29vol5-sec 1910-147.xml.

Code of Federal Regulations (CFR). 2012f. 29 C.F.R. 1926.502. http:// www.gpo.gov/fdsys/pkg/CFR-2012-title29-vol8/pdf/CFR-2012-title29vol8-sec 1926-502.pdf.

Chen H-S, Portier K, Ghosh K, Naishadham D, Kim H-J, Zhu L, Pickle LW, Krapcho M, Scoppa S, Jemal A, Feuer E. 2012. Predicting USand state-level cancer counts for the current calendar year. Part I: Evaluation of temporal projection methods for mortality. Cancer 118: 1091-1099.

CMR, Chemical Market Report, later ICIS Chemical Business Americas. Chemical profile (for different chemicals). Available at ProQuest.

Code (United States Code). 2011a. U.S.C. 655(b)(5). http://www.gpo. gov/fdsys/search/home.action.

Code (United States Code). 2011b. 29 U.S.C. 655(b)(2)-(4), see $2011 \mathrm{a}$.

Code (United States Code). 2011c. 29 U.S.C. 655(a).

Code (United States Code). 2011d. 29 U.S.C. 654(a)(1).

Code (United States Code). 2011e. 29 U.S.C. 657(a).

Code (United States Code). 2011f. 29 U.S.C. 657(f).

Code (United States Code). 2011g. 42 U.S.C. 11001-11050.

Code (United States Code). 2011h. 42 U.S.C. 11023(c).

Code (United States Code). 2011i. 15 U.S.C. 2607(b).

Cowling DW, Yang J. 2010. Smoking-attributable cancer mortality in California, 1979-2005. Tob Control 19(Suppl 1):i62-i67.
Environmental Protection Agency (EPA). 2004. Toxic chemical release inventory reporting forms and instructions. 2003 (Revised). Section 313 of the emergency planning and community right-to-know act (Title III of the Superfund Amendments and Reauthorization Act of 1986). http:// www.epa.gov/tri/reporting_materials/rfi/ry2003rfi.pdf

Environmental Protection Agency (EPA). 2005. Toxics Release Inventory (TRI) Basis of OSHA Carcinogens. http://www.epa.gov/tri/ trichemicals/OSHA/OSHA_carcinogen_table_2011.pdf.

Environmental Protection Agency (EPA). 2008. Overview. Office of Pollution Prevention Toxic Laws and Programs. http://www.epa.gov/ opptintr/pubs/oppt101-032008.pdf.

Environmental Protection Agency (EPA). 2010. List of lists. Consolidated list of chemicals subject to the community right-to-know act (EPCRA), comprehensive environmental response, compensation and liability act (CERCLA) and Section 112 of the clean air act. http://www.epa.gov/tri/ trichemicals/reg_requirements/list_of_lists_revised_7_26_2011.pdf.

Environmental Protection Agency (EPA). 2013a. TSCA Chemical Substance Inventory. http://www.epa.gov/existingchemicals/pubs/ tscainventory/basic.html.

Environmental Protection Agency (EPA). 2013b. TRI explorer release reports. http://iaspubs.epa.gov/triexplorer/tri_release.chemical.

Environmental Protection Agency (EPA). 2013c. Chemical data reporting. http://www.epa.gov/oppt/cdr/index.html.

ERG, National Opinion Research Center. 2009. Final report: OSHA data initiative collection quality control: Analysis of audits on CY2006 employer injury and illness recordkeeping. (Also final reports for 1998, 2001, 2004.)

Federal Register (FR). 1983a. 48 Fed.Reg.53280, 53342 (November 25, 1983) Federal Registers before 1994 are available at www.heinonline. org, a subscriber service.

Federal Register (FR). 1983b. 48 Fed Reg 53280, 53328 (November 25, 1983).

Federal Register (FR). 1987a. 52 Fed. Reg. 31852, 31880 (August 24, 1987)

Federal Register (FR). 1987b. 52 Fed. Reg. 31852, 31879 (August 24, 1987).

Federal Register (FR). 1997. 62 Fed. Reg. 6434 (February 11, 1997) www.gpo.gov/fdsys/browse/collection.action?collectionCode $=$ FR

Federal Register (FR). 2001. 66 Fed. Reg. 5916, 6083 (January 19, 2001).

Federal Register (FR). 2012a. 77 Fed. Reg. 17574 (March 26,2012).

Federal Register (FR). 2012b. 77 Fed. Reg. 17574, 17584 (March 26, 2012).

Frazis HJ, Ilg RE. 2009. Trends in labor force flows during recent recessions. Mon Labor Rev 132(4):3-18.

Friedman LS, Forst L. 2007. The impact of OSHA recordkeeping regulation changes on occupational injury and illness trends in the US: a time series analysis. Occup Environ Med 64:454-460.

GAO Government Accounting Office. 1992. Briefing report to congressional requesters: Occupational safety and health. Employers experiences in complying with the Hazard Communication Standard. GAO HRD-92-63BR. Washington, DC.

Haviland A, Burns R, Gray W, Ruder T, Mendeloff J. 2010. What kinds of injuries do OSHA inspections prevent? J Saf Res 41:339-345.

International Agency Research for on Cancer (IARC). 1987. IARC monographs on the evaluation of carcinogenic risk to humans. Overall evaluations of carcinogenicity: An updating of IARC Monographs Volumes 1 to 42. Supplement 7. World Health Organization. Lyon, France. http://monographs.iarc.fr/ENG/Monographs/PDFs/index.php. 
International Agency Research for on Cancer (IARC). 1994. IARC monographs on the evaluation of carcinogenic risk to humans. Some industrial chemicals. Vol. 60. World Health Organization. Lyon, France.

International Agency Research for on Cancer (IARC). 1995. IARC monographs on the evaluation of carcinogenic risk to humans. Dry cleaning, some chlorinated solvents and other industrial chemicals. Vol. 63. Lyon, France: World Health Organization.

International Agency Research for on Cancer (IARC). 2011. Agents classified by the IARC monographs, Vols. 1-100. http://monographs. iarc.fr/ENG/Classification/index.php.

Ind. Union (Industrial Union Department, AFL-CIO v. American Petroleum Institute). 1980a. 448 U.S. 607, 642.

Ind. Union (Industrial Union Department, AFL-CIO v. American Petroleum Institute). 1980b. 448U. S.607, 656.

Kim H, Fay MP, Feuer EJ, Midthune DN. 2000. Permutation tests for joinpoint regression with application to cancer rates. Stat Med 19:335351.

Kim H, Fay MP, Yu B, Barrett MJ, Feuer EJ. 2004. Comparability of segmented line regression models. Biometrics 60(4):1005-1014.

Mendeloff J, Gray WB. 2005. Inside the black box: How do OSHA inspections lead to reductions in workplace injuries? Law Policy 27:219-237.

National Cancer Institute (NCI). 2013a. Surveillance Research: Joinpoint regression program. http://surveillance.cancer.gov/joinpoint.

National Cancer Institute (NCI). 2013b. Statistical methodology and applications branch and data modeling branch. Joinpoint regression program. Version 4.0.4 (May, 3013). Surveillance Research Program, National Cancer Institute. https://surveillance.cancer.gov/joinpoint/download.

Nelson NA, Kaufman J, Kalat J, Silverstein B. 1997. Falls in construction: Injury rates for OSHA-inspected employers before and after citation for violating the Washington State fall protection standard. Am J Ind Med 31:296-302.

National Institute Occupational of Safety Health (NIOSH). 2011 Registry of Toxic Effects of Chemical Substances (RTECS). http://www. cdc.gov/niosh/rtecs/RTECSfeatures.html.

National Library of Medicine (NLM). 2012. Hazardous Substances Data Bank in TOXNET. http://toxnet.nlm.nih.gov/cgi-bin/sis/htmlgen?HSDB.

National Toxicology Program (NTP). 2011. Report on Carcinogens.12th Edition. Public Health Service. U.S. DHHS. http://ntp.niehs.nih.gov/go/ roc12.
Oleinick A, Zaidman B. 2004. Methodologic issues in the use of workers' compensation databases for the study of injuries with days away from work. I. Sensitivity of case ascertainment. Am J Ind Med 45:260-274.

Oleinick A, Zaidman B., 2010a The law and incomplete database information as confounders in epidemiologic research on occupational injuries and illnesses. Am J Ind Med 53:23-36.

Oleinick A, Zaidman B. 2010b. The need for data harmonization-A response to Boden and Ozonoff. Am J Ind Med 53:854-855.

OSHA. 1987. Office of Regulatory Analysis. Occupational Safety and Health Administration. 1987. Preliminary regulatory impact and regulatory flexibility analysis of the proposed revision in the Hazard Communication Standard (29 CFR 1910.1200). II. Benefits @II-2. U.S. Department of Labor. Document ID: OSHA-H022D-2006-0913 - 0232. http://www.regulations.gov

OSHA. 1988. Office of Health Compliance Assistance. OSHA Instruction CPL 2-2.38B. Appendix: Carcinogen Labelling (same in CPL 2.38C, effective October 22, 1990; CPL 02-02-038 (2.38D), effective March 20, 1998) http://www.osha.gov/pls/oshaweb/owadisp. show_document?p_table=DIRECTIVES\&p_id $=1551$.

OSHA. 2004. Directive CPL 02-00-135 at general guidance: Chapter 5, Question 5 (December 30, 2004). http://www.osha.gov/pls/oshaweb/ owadisp.show_document?p_table=DIRECTIVES\&p_id=3205.

Policy Planning Evaluation, Inc. (PPE). 2009. Revised final report. Data and analysis in support of an economic analysis of proposed. changes to the OSHA Hazard Communication Standard. Herndon, VA: http://www. regulations.gov/\#! searchResults;rpp $=10 ; \mathrm{po}=0 ; \mathrm{s}=\mathrm{OSHA}-\mathrm{H} 022 \mathrm{~K}-$ 2006-0062-0550.

Rothman KJ, Greenland S, Lash TL. 2008. Modern epidemiology Philadelphia, PA: Lippincott Williams \& Wilkins.

Ruser J, Wiatrowski W. 2013. Restricted work due to workplace injuries: A historical perspective. Mon Labor Rev 13(3):31-43

Schoen RE, et al. 2012. Colorectal-cancer incidence and mortality with screening flexible sigmoidoscopy. N Engl J Med 366:2345-2357.

\section{SUPPORTING INFORMATION}

Additional supporting information may be found in the online version of this article at the publisher's web-site 